\title{
A!
}

This is an electronic reprint of the original article.

This reprint may differ from the original in pagination and typographic detail.

Vaittinen, Tuomas; McGookin, David

\section{Phases of urban tourists' exploratory navigation}

Published in:

DIS 2016 - Proceedings of the 2016 ACM Conference on Designing Interactive Systems: Fuse

DOI:

$10.1145 / 2901790.2901795$

Published: 04/06/2016

Document Version

Peer reviewed version

Please cite the original version:

Vaittinen, T., \& McGookin, D. (2016). Phases of urban tourists' exploratory navigation: A field study. In DIS 2016 - Proceedings of the 2016 ACM Conference on Designing Interactive Systems: Fuse (pp. 1111-1122). ACM. https://doi.org/10.1145/2901790.2901795

This material is protected by copyright and other intellectual property rights, and duplication or sale of all or part of any of the repository collections is not permitted, except that material may be duplicated by you for your research use or educational purposes in electronic or print form. You must obtain permission for any other use. Electronic or print copies may not be offered, whether for sale or otherwise to anyone who is not an authorised user. 


\title{
Phases of Urban Tourists' Exploratory Navigation: A Field Study
}

\author{
Tuomas Vaittinen, David McGookin \\ Department of Computer Science, Aalto University, Espoo, Finland \\ tuomas.vaittinen@aalto.fi, david.mcgookin@aalto.fi
}

\begin{abstract}
There is a lack of widely available mobile map applications that effectively support pedestrian tourists who prefer the freedom of exploring their surroundings, and might not have an explicit destination they are trying to reach in mind. Although research systems to support such exploratory navigation have been developed, these are often only studied in controlled trials. It is therefore unclear if researchers are covering all types of navigation tourists do. To get a comprehensive picture of tourists' navigation, we carried out a field study with 16 tourists, shadowing them during part of their visit to Helsinki. Our findings support designers of mobile applications by describing the phases and dynamics of exploration and wayfinding, as well as how existing popular navigation tools are used during exploration. The phases contribute towards a framework for assessing existing tools and developing new ones to cover all navigation activities tourists undertake. We present 5 design implications to support creating tools that take into account the real-world insights collected in the study.
\end{abstract}

\section{Author Keywords}

Exploratory navigation; pedestrian navigation; foraging; mobile applications; field study; shadowing; tourism

\section{ACM Classification Keywords}

H.5.2. Information interfaces and presentation (e.g., HCI): User Interfaces --- User-centered design

\section{INTRODUCTION}

Tourists are a significant user group, with 1.1 billion tourist arrivals worldwide in 2014 [34]. Tourists spend most of their day in an unfamiliar environment and move around a lot, so navigation plays an especially important role in their activities. A person's needs related to navigation naturally depend on the specific task that he or she is carrying out. Allen [3] categorized navigation tasks according to three core objectives: travel with the goal of reaching a familiar destination, travel with the goal of reaching a novel

\footnotetext{
Permission to make digital or hard copies of all or part of this work for personal or classroom use is granted without fee provided that copies are not made or distributed for profit or commercial advantage and that copies bear this notice and the full citation on the first page. Copyrights for components of this work owned by others than the author(s) must be honored. Abstracting with credit is permitted. To copy otherwise, or republish, to post on servers or to redistribute to lists, requires prior specific permission and/or a fee. Request permissions from Permissions@acm.org.

DIS 2016, June 04 - 08, 2016, Brisbane, OLD, Australia

Copyright is held by the owner/author(s). Publication rights licensed to ACM. ACM 978-1-4503-4031-1/16/06 . \$15.00

DOI: http://dx.doi.org/10.1145/2901790.2901795
}

destination, and exploratory travel with the goal of returning to a familiar point of origin. Existing mobile navigation systems however, largely support only one of these. For example, most navigation tools, and mobile map applications in particular, aim to direct users to novel destinations using the most efficient (usually fastest) route. However, Brown [6] and Brown et al. [7] found that tourists often do not want to create explicit route plans but navigate in a roughly correct manner and make detours at will. How common the identified behavior was, or how tourists move from one navigation goal to another was not reported. To build more optimal systems for tourists, we would need to know more comprehensively how tourists navigate as a whole, how they switch between different types of navigation, what happens during exploration and what parts of the navigation are not yet optimally supported by existing navigation tools (both research and commercial). For that, data about how navigation goals evolve and what triggers each activity is needed, and this has to be collected in context by observing real tourists.

This paper supports designers of mobile applications by describing the richness of the dynamics of exploration and wayfinding, as well as how the existing popular navigation tools are used. We shadowed 16 tourists $(5$ small groups and 4 individual tourists) and logged their mobile phone usage while they visited the center of Helsinki, Finland. Our results describe how the tourists' navigation progressed in phases of in-situ planning, in-situ navigation, exploration and reflection and how they moved through the phases fluidly reacting to the opportunities they saw around them. We also reveal what strategies tourists used in exploration and how they collaborated with other people in their group.

\section{RELATED WORK}

\section{Navigation}

Montello and Sas [22] describe navigation to be goaldirected movement through the environment, consisting of wayfinding and locomotion. Wayfinding involves planning on where to go and how to get there. Locomotion consists of moving successfully in the direction one intends with the help of perceptible landmarks. Allen [3] has categorized navigation tasks as: travel with the goal of reaching a familiar destination (for example home, work or other previously visited destination), travel with the goal of reaching a novel destination (a definable place with a location but one which has not been previously visited e.g. a newly opened restaurant), and exploratory travel with 
the goal of returning to a familiar point of origin (for example spending an hour wandering around one's hotel before going to bed). The navigation categories differ both in the amounts of planning and en-route decision making involved. For example, exploratory travel minimizes the pre-travel planning, whilst the goal to reach familiar destination reduces the amount of en-route decision making. Typically, studies of novel technology on pedestrian navigation focus solely on one category, assuming the task persists until the goal is reached.

\section{Pedestrian Tourists' Navigation Needs}

There exists a substantial amount of research on tourists' behavior, and their navigation needs differ in important ways from everyday situations. Tourists tend to leave their plans deliberately ambiguous. Decisions are often easier to make when all the information available at the actual location is at hand, i.e. when one has arrived near the planned destination. Therefore, fixed route plans are avoided and information from the environment is relied on heavily. Pedestrians can often make ad-hoc changes, such as taking shortcuts that are not visible in maps. [6,7]

Relatedly, Vaittinen et al. [31] studied an image-based turnby-turn navigation prototype, finding pedestrian tourists would have preferred less strict navigation guidance and instant access to the approximate direction they plan to go. They would have wanted to pay more attention to their surroundings and the pleasurable aspects of it.

Comparing Allen's [3] wayfinding categories with previous research on tourists, it seems the tourists would like to perform exploratory travel while still aiming to reach novel destinations. Unfortunately, how these activities are interleaved and what triggers each activity is not clear from existing literature. In addition, whilst existing navigation systems focus primarily on achieving geographical goals, tourists' goals may not often be geographically driven.

\section{Navigation Systems for Pedestrians}

Travel to novel destinations has been traditionally the focus of navigation-related HCI research, and maps and other navigation prototypes have been created to support it. Some research systems help the user to plan a route that is not only efficient but stimulating and pleasant as well $[11,25]$. Although not specifically made for tourists, these systems could support focusing on the pleasurable aspects of the city. Additionally, GUIDE made for visitors to the city of Lancaster in the UK, and one of the earliest mobile systems focused on tourists, optimized the order of attractions to visit taking into account the opening hours and queues [9].

While travelling to a novel destination is the core focus of existing work, researchers have also begun to recognize the importance of the journey to the destination, as well as the destination itself. Eyes-free interaction techniques, to allow focusing on the environment and provide "crow flies" bearing feedback to avoid the constraints of strict turn-byturn approaches have been developed [2,15,17,19,24,26].
Some are made specifically tourists in mind [19,24,26], some for more general urban use $[2,15,17]$.

For more exploratory travel, early location-aware systems for visitors provided basic support by displaying information about nearby points-of-interests $[1,9,10]$. These features support tourists in cases where they themselves decide to initiate exploration and want to find nearby sights.

Other systems provide system-initiated commentary [5] or alerts [16] when tourists approach sights. They support finding sights, or information about them, even when exploring randomly. However, of the systems described here, only GUIDE reports results of a field trial with actual tourists [5,9]. It is not clear how large a part of tourists' navigation goals such existing work actually covers and how they integrate into the day of the tourist.

\section{Understanding Tourists' Exploratory Travel}

The movement of tourists has been tracked in many studies outside HCI field [e.g. 4,18] and the information has been used in planning and managing attractions. Lew and McKercher [21] identified movement patterns varying from point-to-point travel to more opportunistic exploratory paths. The studies have concentrated on the paths itself and the personality and travel styles of the tracked tourists, so they do not reveal much about how the decisions about the route are made and how they could be supported.

\section{Tourists' Information Needs}

The decisions tourists make are based on the information they are able to collect from the environment and from guides, maps and other travelers. Increasingly, this information is available in digital form and can also be accessed on the move using smartphones.

Post-trip interviews of US tourists by Wang and Fesenmeier [33] suggested that, in addition to communication and fun, smartphones are used for information searches and facilitating the trip. They discovered smartphones were handy and effective in finding information about dining, things to do, etc. However, an in-depth study by Brown et al. [7], on smartphone use in ad-hoc information queries, identified that many of these searches fail, and people have to rely on 'luck' and hope they 'stumble over' the places they were interested in, or will instead 'give up'.

Mobile information needs have been studied in everyday life as well. A Study by Carrascal and Church [8] revealed that search engines are used for broader information needs, while apps, such as Maps, are used for more specific queries. Users employ multiple sources and share the information to make joint decisions about events to join, for example. This could be something that tourists do as well, and an interesting area to collect information about.

To fill the gaps in the existing research, our study focuses on the following research questions: (1) How do tourists switch between different types of navigation, and how do the underlying goals affect this? (2) How are decisions 
made during exploration? and (3) How, and how successfully, are smartphones and other tools used to support exploration and navigation?

\section{STUDY DESIGN}

To answer these research questions, we carried out an observational study in the center of Helsinki during the summer of 2015. In the study we shadowed 16 tourists (5 small tourist groups and 4 individual tourists) while they visited a part of the city center they themselves had chosen. Answers to our research questions had to be acquired by observing real tourists carrying out their own tasks. Only this way the identified goals and decisions were authentic.

\section{Recruitment}

We advertised the study in hostels and hotels, as well as in the main tourist information center. We also circulated invitations among colleagues and Facebook friends, so they could pass it on to visitors they knew. We were looking for groups of 1 to 4 tourists visiting the city and we offered every participant a gift voucher to a café with value of $15 €$. Participants signed up in a web form and we contacted them by e-mail to confirm their place and time. They were asked to let us shadow them for approx. 1h during their visit.

\section{Participants}

We recruited 16 participants consisting of: 1 group with 4 tourists, 4 groups with 2 tourists and 4 individual visitors. We had 8 female and 8 male participants, and their ages varied from 16 to 83 (avg. 40). One participant came from Mexico, one couple from India and another from Australia but the rest came from different parts of Europe: Denmark, Germany, Holland, Spain, and UK. See Table 1.

For 12 participants, this was their first trip to the city. Group 3 had visited it once before and two individual participants (Group $6 \&$ 9) had visited it multiple times. All, except Group 6, were visiting other cities during their trip, so typically this stop was just one of the many they made during their trip. The specific areas they chose to visit were new to 7 groups, and included both new and familiar areas for the tourist in Group 9. The tourist in Group 6 had a routine of visiting the area (outdoor market), so it was familiar to him. Most popular activities were church visits, as well as just exploring streets and seafront. More details about activities are listed in Table 1.

\section{Method}

Out goal was to, as far as possible, naturally integrate into participants' day. We therefore met them in a suitable coffee shop near an area they had themselves indicated (1 or 2 days in advance) they were interested in visiting. There, we discussed the study and their trip so far, and asked participants to sign the consent for recording the session. The discussion covered what participants were looking for from their trip, how much they had planned it, what tools and information sources they had used in planning it etc. We also asked them which new sight or area they would be interested in visiting next, and how much they knew about the place beforehand.

\begin{tabular}{|c|c|c|c|c|}
\hline ID & Sex & Age & Relation & Activities \\
\hline \multirow{2}{*}{1} & M & 45 & Father & \multirow{2}{*}{$\begin{array}{l}\text { Explored streets and } \\
\text { visited } 2 \text { churches }\end{array}$} \\
\hline & M & 16 & Son & \\
\hline \multirow{2}{*}{2} & $\mathrm{~F}$ & 27 & \multirow{2}{*}{ Couple } & \multirow{2}{*}{$\begin{array}{c}\text { Navigated and visited } 2 \\
\text { churches }\end{array}$} \\
\hline & M & 36 & & \\
\hline \multirow{2}{*}{3} & $\mathrm{~F}$ & 58 & \multirow{2}{*}{ Couple } & \multirow{2}{*}{$\begin{array}{l}\text { Explored park and the } \\
\text { seafront }\end{array}$} \\
\hline & M & 64 & & \\
\hline \multirow{4}{*}{4} & $\mathrm{~F}$ & 51 & Teacher \#1 & \multirow{4}{*}{$\begin{array}{l}\text { Navigated to park, } \\
\text { explored it and the } \\
\text { seafront }\end{array}$} \\
\hline & $\mathrm{F}$ & 36 & Teacher \#2 & \\
\hline & M & 19 & Son of \#1 & \\
\hline & $\mathrm{F}$ & 18 & Daughter of \#1 & \\
\hline \multirow{2}{*}{5} & $\mathrm{~F}$ & 55 & \multirow{2}{*}{ Couple } & \multirow{2}{*}{$\begin{array}{l}\text { Visited church, explored } \\
\text { city and the seafront }\end{array}$} \\
\hline & M & 56 & & \\
\hline 6 & M & 83 & Individual & $\begin{array}{l}\text { Explored outdoor flea } \\
\text { market }\end{array}$ \\
\hline 7 & M & 25 & Individual & $\begin{array}{c}\text { Explored streets and the } \\
\text { seafront }\end{array}$ \\
\hline 8 & $\mathrm{~F}$ & 23 & Individual & $\begin{array}{l}\text { Explored streets, church } \\
\text { and bookstore, } \\
\text { navigated to old stadium }\end{array}$ \\
\hline 9 & $\mathrm{~F}$ & 28 & Individual & Navigated to 2 churches \\
\hline
\end{tabular}

Table 1. Tourist groups and what they did during shadowing

After this we left the café with the participants. No constraints were placed on where participants could go or how they could get there. They were also free to use any method of transport. The researcher shadowed the group observing, collecting data and asking a few questions at key points (such as after switching to a new activity or making other decisions). The questions were related to participants' current activity, for instance the route decisions just made or what interested them in a particular sight. To ask the questions while the things were still fresh in their minds, the researcher had to be present, ruling out the option of leaving the tourists to record their day independently. Participants were free to talk to the researcher during the session, but were told he could provide no assistance on places to visit or how to reach them. As is typical in shadowing studies (see e.g. [20]), the researcher was not trying to be a full member of the group, nor in a completely observatory role (as this would be unnatural for the participants). The experimenter acted as a temporary travel companion of sorts, able to converse with participants, but not take part in decision making or assisting in navigation. After around an hour of shadowing, we conduced a short exit interview in-situ. Participants were compensated with the gift vouchers and the experimenter left, allowing participants to carry on with their trip. 
To record the sessions, the researcher wore a GoPro Hero4 camera in a chest harness. As the experimenter would often be walking further back from the group, one person in each group was asked to wear a small audio recorder around his or her neck to ensure that conversations were clearly recorded. We chose this approach after several pilots to find a balance between good quality recordings but avoiding the equipment "getting in the way". In the pilots the worn GoPro was not found to be distracting by the participants, and did not draw attention from passers by in the way a handheld camera did. The experimenter also carried a GPS logger to ensure an accurate record of the route.

To ensure all participants could use the internet to assist them, we supplied a Nexus 6 Android smartphone with a local SIM card and data plan. Participants were not required to use this device, and could use their own phones and other data sources (guidebooks, paper maps etc.) as well. Whilst, some of users had roaming data plans and could use their personal device, many did not. As the European Parliament has agreed to require pan-European roaming at no extra cost from June 2017 [12], we decided to ensure all participants had mobile internet access. We had considered supplying local SIM cards so participants could use their own devices. However, as those devices might be carrier locked, cards may not be the correct size and participants could not make or receive calls from their own numbers, doing so was determined to be logistically too complex.

The Nexus 6 also ran Lookback screen recording software, and AWARE mobile usage logger [14], to capture the usage sessions as thoroughly as possible. AWARE acted as a backup and stored the GPS location, the state of the display (on/off), applications the participants launched, and texts (e.g. search queries) they typed. No logging software was installed on participant's own devices.

For analysis, the video from the camera, audio file from the recorder, the screen capture from the phone and the screen capture of their route played back were combined to one video file (see Figure 1). Videos were iteratively annotated to identify critical points relevant to navigation. These were labelled and grouped using an informed grounded-theory approach [30] to identify core aspects of tourist navigation.

\section{RESULTS}

The compiled videos from the 9 shadowing sessions contained 9.3 hours of participants' activities (avg. session length $62 \mathrm{~min}$ ). From these, 808 observations were written down, grouped, labeled and analyzed for recurring themes.

Participants were visiting areas that were interesting to them, and for 7 groups it was an area they had not yet visited. Therefore, in terms of Allen [3], the majority of the wayfinding observed in the study was either exploratory travel, or travel to novel destinations. Whilst Allen described exploration as lasting until the person returned to their original starting location, we found that exploration could be undertaken over a much shorter time scale.

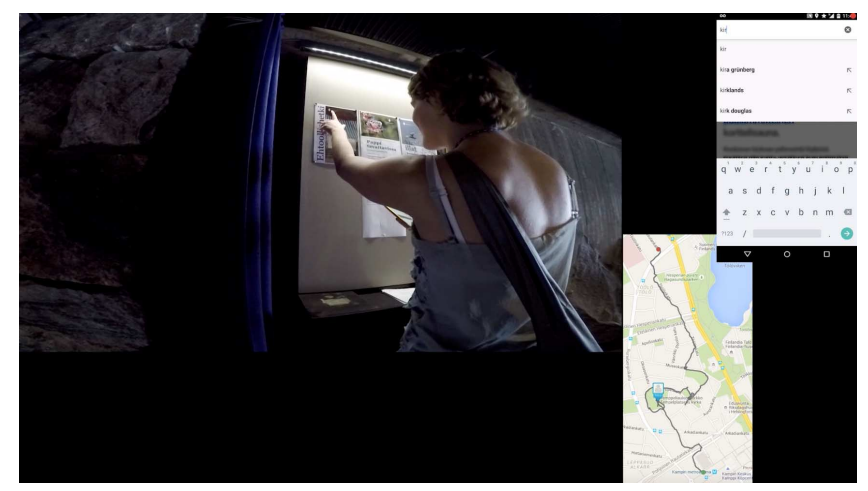

Figure 1. Recordings contained video and audio of the focus and surroundings of the participant, her route and position (bottom right), and a screen capture of the phone (top right)

During the visit participants were free to use any tools they wished, including their own phones and the one we loaned them. 6 groups used a phone during some parts of their shadowing. 3 groups used predominantly the phone we loaned, and in Group 2 one participant used occasionally his own phone while his wife used the one we had lent. For 3 groups, the paper map was the main navigation tool but two of them used also their own phone and the one we loaned for some tasks. The paper maps had been acquired from hostels or tourist information center.

\section{The Phases of Navigation}

Irrespective of the aids used by participants, our analysis revealed a set of clearly defined navigation phases. Participants transitioned dynamically between these different phases during our observations. The general order participants undertook these phases was consistent: in-situ planning, in-situ navigation, exploration and reflection, but participants got temporarily sidetracked many times. For example, while navigating to a planned destination, they might see something intriguing and would immediately switch to exploring it. Sometimes complete phases were skipped, for example when the destination was in view the whole time, removing the need for a navigation phase. Groups 3 and 6 skipped navigation altogether and just explored their surroundings, but the rest of them went through all the phases, at least once. Occasionally, participants would make multiple transitions between phases over a short period. For example, after just deciding to go to a church and starting to orient with a map, another idea emerged and took participants back to planning.

Instead of following a static plan made for the whole day, participants concentrated on the next activity and kept several options open for later: "So we're trying to get information either shortly before or when we're there, like we did. Like we do now." (Male, 45y, German, Group 1)

Figure 2 shows an excerpt of the activities of Group 2, and how they progressed from one phase to another. This excerpt includes all the phases. However, as described above, participants moved through the phases fluidly, reacting to the opportunities they saw around them. This 


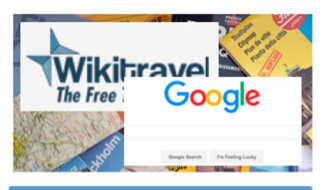

Pre-planning

1. Read Wikitravel for overview

2. Google "alternative [city]"

3. Look for paper map with local tips (no success)

4. Look for free walking tour (no success)
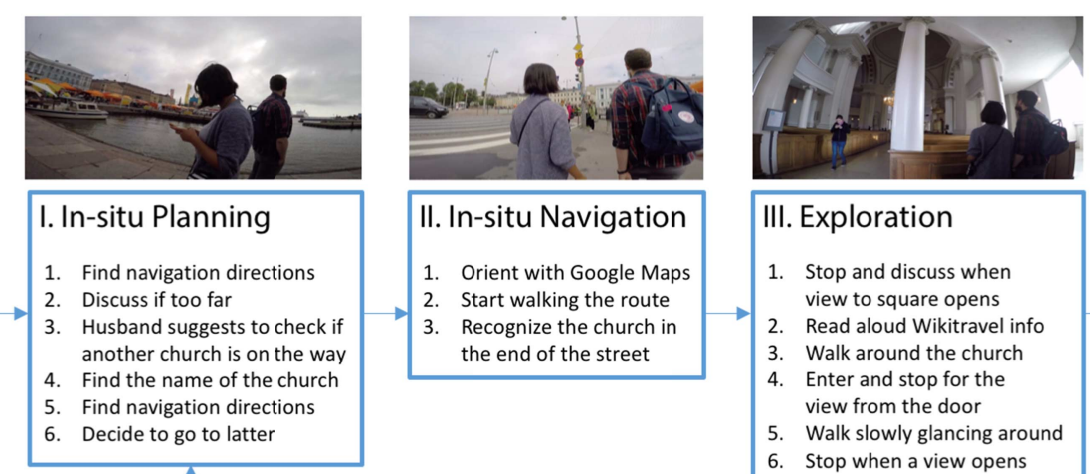

III. Exploration

1. Stop and discuss when view to square opens

2. Read aloud Wikitravel info

3. Walk around the church

4. Enter and stop for the

view from the door

5. Walk slowly glancing around

6. Stop when a view opens to the main altar

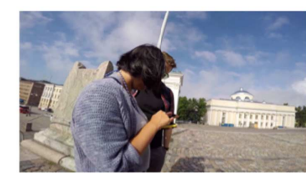

IV. Reflection

1. Exit the church

Walk a bit from the door

3. Read Wikipedia

4. Discuss the details on the ceiling

Figure 2. Excerpt of activities of Group 2 and iteration of the phases of navigation: after reflection in-situ planning started again

resembles what Suchman [29] described as plans and situated actions. Plans are resources for situated action but do not fully determine its course. We now describe each of the phases and their characteristics in more detail.

\section{Planning}

With planning we refer to the activity of choosing the places to visit and deciding the means to get to them. Planning was largely concentrated into pre-planning done in the days preceding a visit to an attraction, and in-situ planning that was carried out just before starting an activity.

\section{Pre-planning}

All participants had carried out some pre-planning before we shadowed them. However, the detail of these varied significantly. Three groups had decided on only the first thing they wanted to see, but expected to have more time and would choose where to go afterwards ad-hoc. The other 6 groups had a few things that they wanted to visit. It was not important to make into all of them but some had higher priority than others. The pre-plans were meant to be tentative and participants refined them as the day progressed. The pre-plans were done with limited information and could not take into account all the situations that occurred during the day.

Additionally in some cases, participants had been uncertain of opening hours while planning: "I want to visit this and this and this, but I don't know what time they open and they close. [...] I don't know if one place is better in the morning or the afternoon." (Female, 34y, Spanish, Group 4). Even if opening hours were available on the web, there was little support to track and compare them from multiple places so as to support effective planning. Keeping track of multiple places was cumbersome.

Pre-planning was almost exclusively supported by web searches. Web sites like VisitHelsinki.fi, Wikitravel.org and TripAdvisor.com were used as primary search sources on places to visit and mobile 'apps' were not used. Group 5, which was on a longer trip, had purchased an electronic guidebook for their iPad. Six groups had also got some tips from other travelers, or friends or relatives living in the city.
None of the participants had downloaded a local 'app' (e.g. tour guide or transit planner) to their own phones. This was surprising, but was largely due to the assumption that participants felt them to be unnecessary. Visitors were not visiting Helsinki for a long time so they felt they would be able to find enough things to do without such apps. Offline applications, which store content on the device, are often significantly larger than those that can access the internet. Participants did not want to free up space on their devices (e.g. by removing photographs or other content) to install such large apps. This does indicate that installing and testing separate apps for each city was considered arduous and the ones with worldwide coverage were preferred.

\section{In-situ planning}

As participants only carried out limited pre-planning, plans were refined and developed in-situ just before starting the activity. The amount of details in the plans participants created in-situ varied considerably. In a detailed case, the in-situ planning could include choosing a specific sight and creating a navigation plan to get there. On the other hand, the simplest plans included only a direction that looked interesting and a decision to walk towards it: "We can walk this way. That's a new way for us. This part we have not seen." (Male, 64y, Indian, Group 3). In these cases, the goal was to immerse oneself in a pleasurable environment and see something new. Two groups kept the plans as simple as possible for the whole duration of their participation, Group 2 made only very specific plans, and the remaining six groups alternated between specific and simple plans.

All six groups whose pre-plans included several sights used the phone or paper maps at some point during the session. These were used to find new options to match their situation better than the ones created during pre-planning. Participants could make finalized plans about restaurants or route only when they knew where they were when they wanted to eat, or go to a specific sight. Wikitravel, Foursquare, and blogs by other travelers, provided information about restaurant options and pre-planned sights. Providing the information when it was most useful was also the main value that the phone provided to 
participants. This last-minute searching is similar to the 'occasioned searches' identified by Brown et al. [7]. The three groups that relied on paper maps liked the simplicity, and the fact that the main sights were often easy to pick out since the maps presented these as distinctive 3D drawings.

When the planning of the next activity required finding information about the options and focusing on the information sources, like phones and paper maps, participants separated themselves, disengaging from the current experience by taking a few steps aside to be in a less crowded spot. After they had some options in mind, they needed info about the distances to them. When the destination was not in view, 4 groups used Google Maps on the phone for providing an estimation of the time to walk there. The time was either provided directly by Maps after calculating the route, or participants zoomed out the map to get both the destination and the current GPS position simultaneously on the screen to make an estimation: (Repeating what she had read from Wikitravel) "There's three places to see: the white, the red and the rock (church). We've seen the white and the red is ... about 10 min away from here” (Female, 27y, British, Group 2).

If participants found something within a reasonable walking distance, they looked for the route. All groups considered the scenic aspects of the route, like finding a route passing by a park or seafront. This indicates an underlying goal of experiencing the pleasurable and enticing aspects of the city, not just reaching a certain sight. The colors used in maps helped in assessing if there would be parks or water on the way, but more support for the in-situ planning phase was desired: "What kind of streets are nice to walk around. Or if there is some nice park also next to the water, or nice [open-air] market for example" (Female, 28y, Mexican, Group 9). Applications like Foursquare were found to be too focused on suggesting businesses, whilst Google Maps focused on 'utilitarian' navigation, just showing the shortest routes. Participants did not find effective support to find nice paths and neighborhoods to stroll around.

\section{Fluidity of In-situ Plans}

Created in-situ plans were not fixed. All 7 groups that had at some point a specific in-situ plan, changed their plan as it was executed. When participants saw something that fitted their needs at the time, they readily postponed or abandoned their original plan: "Actually, we're heading there but before anything else... a bookstore. I cannot pass by a bookstore." (Female, 23y, Danish, Group 8)

Two groups stated while planning that they are also open to changing their plans for any options that appear while walking to their destination. Again, the goal was to experience the best parts of the city, not necessarily see a specific sight. In any case, plans were based on uncertain information, so something concrete that was in front of participants eyes often appealed more. In most cases, participants returned to the original plan, even if the detour had taken them an hour (as in the case of bookstore above).
One plan of finding a café got abandoned altogether when an art exhibition in the same floor proved more interesting for Group 1.

Ideas and plans for future activities were collected all the time when participants came across something interesting. Food options with a tempting aroma passed by on the market, and popular looking sights seen from a tram were noted and returned to: "I'd like to see (the church) before I leave. Because this morning when I was in the tram I saw a lot of people coming out from there. I said: What is this? [..] So I checked the map" (Female, 34y, Spanish, Group 4).

\section{Collaborative Planning}

For the 5 groups that were not solo travelers, all planning was a collaborative process, requiring negotiation amongst group members. One of the group members took a primary role, holding the information source and actively pursuing the task, while the others adopted a secondary role, phasing in and out of the planning depending on the stage reached. Typically, the secondary participants looked at the phone or map when there was concrete information about a potential destination or the route to reach it. During times when their travel companions looked for the local names of the sights or were in other intermediate stages, they took photos and paid more attention to the environment around them.

That one member of the group was "in charge" was not necessarily by choice, but dictated by the tools being designed for single person use. The need to concentrate on the device took the whole attention of one group member away from interacting with others and could create some tension inside the group. This was alleviated by sharing some bits of the information to include other members of the group in the planning. This way everybody's viewpoints could be used at least intermittently:

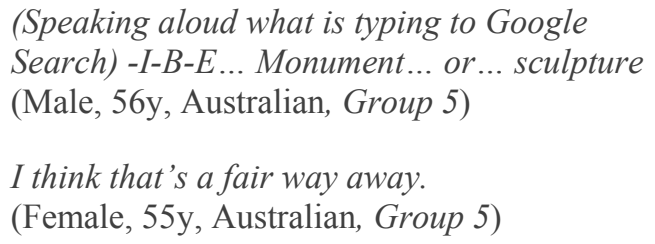

The in-situ planning generally stopped when participants had a clear enough idea of what they wanted to see next, and could transition to navigating. This required the planner to share the plan within the group and reach a consensus about it. At that point, other group members could still suggest alternatives, which could take them back to planning, so the borders of the navigation phases were not clear-cut (see also the In-situ Planning box in Figure 2):

Oh it's quite away. Half an hour [...] So we need

to go... (Starts orienting with the route)

(Female, 27y, British , Group 2)

Is there the white building, is it on the way?

(Male, 36y, British, Group 2) 
(Uses Google Search, Wikitravel and Google Maps silently $1 \mathrm{~min}$ ) The bigger cathedral is actually close, so should we go see that first? (Female, 27y, British, Group 2)

When the plan satisfied everyone and was detailed enough to start navigating, groups started orienting with the plan.

\section{In-situ Navigation}

In-situ navigation refers to the activity where tourists follow some form of navigation plan and move through the environment accordingly. If users had only determined a vague plan, for example without a clear geographical destination such as just exploring an interesting looking direction, or if the destination was already visible, participants simply walked towards it, without the need for intermediate landmarks or other navigational aids.

However, in case the destination was not in view, participants had looked for some instructions to get there in the planning phase. When transitioning to navigation, participants had to orient the instructions with the environment around them. Google Maps on the phone provided a blue dot at the GPS location of the phone and a small arrow to indicate which direction the user is pointing the phone. However, the compass on the phone (and hence the arrow) was unreliable and caused two groups to walk in an incorrect direction (90 to 180 degrees wrong).

Participants were free to use any method of transport they wished. Group 4 used a tram, whilst the rest chose to walk to their destinations (the city center is compact and affords on-foot navigation). Using the tram brought up many questions: what do the stops look like?, which tram to take?, how to know if it is going on Saturday?, how to pay?, when to step out from the tram?, etc. A paper map was used to select the correct tram route, and one participant's experience was used to understand how to buy tickets, but majority required trial and error. The incident highlights the amount of issues tourists need to solve before using public transport in a new city, so digital navigation tools should support tourists more comprehensively, providing the tacit knowledge that locals often have but is unclear to tourists.

As described in the sections above, participants often transitioned from navigation temporarily when they saw something worth exploring en-route, and afterwards transitioned back to navigation. More persistent transition from navigation to exploration happened when getting the destination in view and recognizing it. The cognitively demanding part was over and all group members could more freely pay attention to the pleasurable aspects of their surroundings, and effect a transition to exploration. "Oh there's the church. Now we can just walk towards it." (Female, 28y, Mexican, Group 9)

\section{Collaborative Navigation}

In groups with more than one participant, even where only one device was being used to show a map, navigation was collaborative. The group member in primary role who had the map or the phone shared the directions at waypoints enroute, whilst other group members queried him or her for confirmation about the route to take if they were walking slightly ahead: "We can check, we need to look for tram number 3" (Female, 34y, Spanish, Group 4)

Sharing the directions allowed all members of the group to participate in recognizing landmarks and interpreting public transport information. Collaboration was even more frequent when participants were walking to a destination in view. Then anyone could suggest which path to take.

\section{Exploration}

Explorative behavior happened on many levels. As already discussed, participants transitioned temporarily from navigation to exploration when something interesting was seen en-route. People explored streets, sights and tables on a market place. When walking on the streets they chose the path to take based on what intrigued them at each direction, like a glimpse of the sea at the end of a street. Exploration of architecturally interesting sites, such as churches, started already from the outside. Participants were taking photos, inspecting the details of the building and discussing what they saw. Then, the building was entered and the contents of it were explored as well.

\section{Phases of Exploration}

When getting the first unrestricted view of a sight, and especially if it happened suddenly, there was a need to make sense of it. For example, when a church came to a view behind a corner, or when participants entered it, they stopped to glance around, comment on details they saw and ask questions about them: "Do you know anything about the text? Is it Cyrillic or what?" (Male, 45y, German, Group 1)

After stopping and getting an overview of the area, participants started to walk around to inspect the details and discuss them. In case walking revealed a new view to a previously blocked part of the sight, stopping and making sense of the view happened again. Participants walked closer to examine smaller details, and stopped to study less accessible details, such as paintings on the ceiling, from a distance. They discussed these with their travel companions and pointed aspects of them to others.

The exploration included also looking for more information about the details participants saw. Information texts next to statues were read. Participants also asked many questions from the researcher about the things they saw. In addition to a couple of information queries, the phone was not really used in exploration. Apps did not provide much value for exploration, and participants wanted to keep their focus on their immediate surroundings.

\section{Value in Exploration}

Motivations behind choosing certain items for closer inspection varied widely. People had hobbies, such as sewing quilts, which made them interested about repetitive patterns on church walls, or they were studying languages and old dictionaries were interesting to them. Local things 
specific to the area were of interest to everyone: "When we travel we try to buy local.” (Male, 45y, German, Group 1)

When exploring streets, pleasurable views and buildings with distinctive architecture were sought after: " $I$ 'd say I mostly go for food or for views, unique churches or buildings." (Male, 25y, Dutch, Group 7)

The things that provided the most excitement to participants were the ones that they had not expected to come across, and which revealed something about the local life. The locals using seafront facilities for washing rugs, or a $19^{\text {th }}$ century fire station tucked between residential buildings were commented with the greatest enthusiasm: "That's why I go walking. To see things like that. Never expected it to be a fire department. I expected to be a town hall or a church. [...] It's out of place" (Male, 25y, Dutch, Group 7). Therefore, for tools, focusing on the major sights might not be enough. Although the serendipitous discovery of these places was an important factor in the excitement, helping the tourists to experience more unexpected things could improve their experience considerably.

\section{Finishing Exploration and Transitioning to Next Phase}

Rounds [27] has suggested that museum visitors' exploratory behavior would be analogous to foraging animals. Rather than exhaustively inspecting all exhibit elements, a visitor would devote time only to the most interesting ones with the goal of maximally satisfying his or her curiosity. This resembles animal food searching behavior, where the animal needs to decide when the costs of searching for food from its current surroundings exceed the value it generates, so the animal will move to a new area to maximize the value it gets [28]. Furthermore, Adaptive Interaction framework [23] states that the constraints from the environment, the limits of human information processing system, and what a person values most at a particular time, shape the selection of exploratory strategies the person can choose. In case anyone of these constraints is missing, the strategy space is unbounded.

A lot of the exploration observed in the study was on some level exhaustive, contrary to Rounds' suggestion. For example, exploring a churchyard led to walking a full circle around the church before stopping and entering it. Similarly, when looking at tables at a flea market the participant walked though all the isles in sequence (see Figure 3) before transitioning to planning the next activity.

Since many of the sights participants visited were quite small, it was possible to walk around them quite exhaustively. Typically, the exploration ended and transition to planning the next step started when participants just felt they had seen enough: "We looked at it [church], saw it, went inside it, learned as much as we could, so let's move on" (Female, 27y, British, Group 2)

Two groups had a strict time limit, because they had to catch a bus right after concluding their session. Complying with Adaptive Interaction framework, the additional constraint made participants weigh the expected gains of exploring the city further against having to rush to the bus, and stopped exploring when the gains seemed getting smaller: "I might walk up to that grey building and then start walking back" (Female, 55y, Australian, Group 5). In other words, this constraint made visible the value maximization behavior that foraging theory predicts. In the more exhaustive cases, either the effort required for moving to a new area was considered high, or saving time for something else was of no value to the user, so there was no need to weight the gains of staying or leaving.

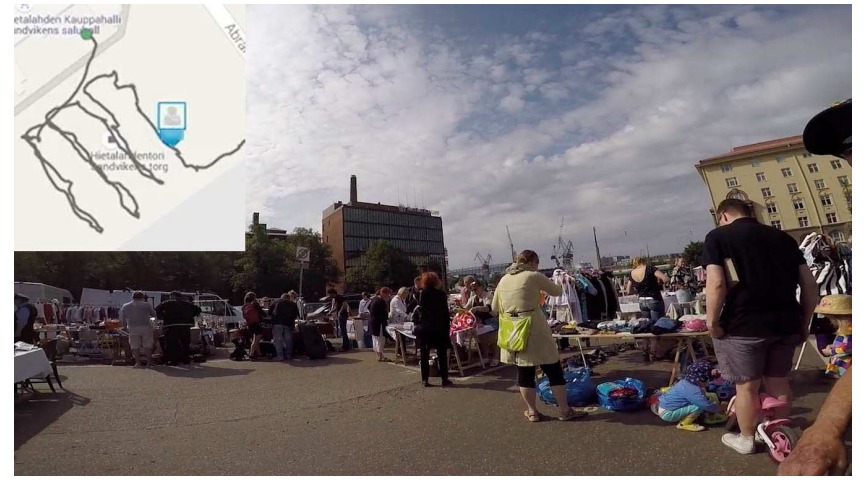

Figure 3. Map on the top left corner shows the route Group 6 took at the flea market inspecting all the isles in sequence

The goal of maximizing the value one gets was also visible in that participants were clearly aiming to maximize the amount of new areas of the city they will see. If they had taken one route a day before, they took another alternative the next time. Participant in Group 7 had even downloaded an application called Fog of World that recorded and visualized on a map view the streets he had walked. "Truly nice to set a trail [..] Makes me to walk more sometimes, or walk a different route that maybe is longer because I want to unfog a different street" (Male, 25y, Dutch, Group 7).

\section{Reflection}

In some cases after stopping the exploration, there was a need to spend some time in reflecting what participants had just seen. Two groups stopped at the outside of a church and looked on-line for more information about the intentions of the architects who designed the churches. In addition, two other groups stopped to check the map of the route they had just taken.

Reflection was done collaboratively, reading the information about the sight, commenting aloud which details one had not seen, with others in the group explaining where they saw them and what they thought about them:

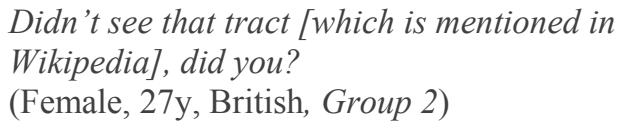


Oh was it with the Cyrillic alphabet?

(Female, 27y, British, Group 2)

Reflection also happened during exploration, with participants comparing what they saw with previous experiences. Reflection could also occur some time later, and not always in-situ. Group 2 mentioned that when they return to their hostel, and have some peace and $\mathrm{Wi}-\mathrm{Fi}$, they would continue to search for information about the details of a church they did not manage to find during the session.

After checking the information that was easily available, participants transitioned back to planning.

\section{Information Needs}

In addition to looking for information about places to visit, navigation to them, and things they see around them, participants were also curious about local habits, food and current local issues. They mostly chose to ask information from the researcher since he was local, and looking for such information on-line would have taken much more effort, often requiring language translation.

When looking for information with the phone about things around or places to see, attempts most likely to fail were either very specific: "why there are stars in the roof of the cathedral", or quite vague: "what to do in Helsinki". Mostly participants' information needs were on the level the web search and sites could handle, though. However, participants were looking for to-the-point answers about things they saw around them, but often found only Wikipedia-style descriptions of city history, so using the web required more effort than would have been optimal.

When looking for any local information, like directions to places they had heard about, participants struggled with the language they were not familiar with. Remembering how the names of places are spelled was already challenging (see the in-situ Planning box, activities 4 and 5, in Figure 2): "I kind of didn't remember what was it called so I went to Wikitravel, because that's where I read about it, and then googled the name of it there and got the directions from Google Maps" (Female, 27y, British, Group 2)

Actual understanding of the local language was naturally also an issue. Some information placed on to sights, especially parks, was written only with the local language so the tourists could not understand it at all. The availability of mobile translation applications was not clear for everyone, so the phone was not really used for these tasks.

\section{DISCUSSION}

\section{Research Questions}

How do tourists switch between different types of navigation, and how do the underlying goals affect this?

Allen [3] identified three categories of navigation tasks. We identified how these tasks fit into broader view of tourists' activities where they appear in quite stable order and iterate as the day goes on. In addition, we observed that the navigation tasks do not necessarily persist until the goal is reached, rather tourists interleave exploratory travel between more geographically oriented travel. They occasionally explore areas they pass through before returning to the original plan, which indicates an underlying goal of experiencing the pleasurable and enticing aspects of the city, not just reaching the sight. They also skip individual phases when, for example, navigation is not needed as the destination can be seen. Brown [6] has found that tourists leave their pre-plans deliberately ambiguous and avoid fixed route plans. Our study confirmed this, but it also revealed more details on dynamics of the plans and resulting activities.

The identified phases contribute towards a framework for assessing existing systems and gaps in them. For example, some systems in the literature support tourists in in-situ navigation phases, letting them keep their visual attention in the surroundings and make detours when they see something interesting $[15,17,19]$. However, these still require the user to specify a destination, so they do not support tourists on an exploration phase walking the streets based on things appearing in front of them. In addition, most of the systems are based on audio feedback, which is difficult when tourists travel in small groups and prefer to converse and collaborate in choosing the things to explore.

How are decisions made during exploration?

Rounds [27] has suggested that museum visitors' exploratory behavior would be analogous to foraging animals and people would pay attention to items most interesting to them and then move on. However, we found that most tourists were quite exhaustive in walking around the sights and inspecting the items on display at churches, for example. Complying with foraging [28] and Adaptive Interaction [23] theories, the value maximization became visible when tourists had additional constraints. When they had a strict time limit and the area to explore was large, tourists clearly weighted the discomfort in rushing to the next activity with the probable gains of exploring further. Tourists aim to maximize the amount of new areas of the city they see and value local things but otherwise have very divergent values they maximize when exploring. Foraging theory is best applied for describing tourists' exploration in the cases where there is not enough time or energy to explore the area exhaustively, or moving to a new area requires little effort.

How, and how successfully, are smartphones and other tools used to support exploration and navigation?

Brown et al. [7] identified that many in-situ information queries on mobile devices fail, while Wang and Fesenmaier [33] had a more positive view on their success. Our study included some examples of failing queries but mostly they succeeded. The most specific and vaguest queries were likely to fail. Carrascal and Church [8] described collaborative use of search with remote friends and family members who are agreeing events to join, for example. Our results show similar collaboration with co-located tourists. 
During planning and navigation, tourists shared plans and navigation directions intermittently, and other members of the group were contributing when they had enough information. Comparing this against our identified phases reveals that during planning the tools provide good support for finding general information about the sights and businesses, as well as distances to them. However, such tools are designed to be used by a single user. Sharing plans, and incorporating others into planning is not well supported, which limits the participation of other group members. The support for dealing with varying opening hours is limited and exploratory support is missing.

\section{Limitations of the Study, and Future Work}

Even during fairly short shadowing sessions we identified rich and evolving movement through navigation phases. However, had we been able to follow them for several hours we might have been able to identify some additional slower occurring patterns. We did interview the participants about the planning they had done before the shadowing and their trip plans for the rest of the days, so we got information for a longer time frame than the shadowing. Furthermore, requiring the tourists to use several hours of their trip to the study would have unnaturally constrained our pool of participants to the small part who stay for longer than the typical city visit of 1-3 days.

We observed pedestrian tourists in an urban environment so our results can be best applied for them. Tourists visiting more rural areas or travelling with car might behave differently and deal with some issues not described here. We were able to recruit quite diverse group of tourists, both by age and country of origin, so they do cover reasonably well the urban tourist user group. Urban tourists are also the largest tourist group in Europe generating 65\% of nights spent in tourism accommodation [13].

The findings of this study form a basis for filling the existing gaps, so future work should implement tools for for example exploration and collaborative navigation. Future work should also observe how tourists take the new tools in use to further validate and expand the findings of this study.

\section{DESIGN IMPLICATIONS}

To highlight the main insights gathered, we present five design implications for mobile applications for tourists.

Tourists' needs are dynamic and evolving. Tools should support switching between interfaces that best support each of these. Current navigation tools rely mainly on maps and list. These work well for some needs but not for all. For example, exploration would benefit from interfaces that would register the information spatially to the objects it refers to removing the need to divert the focus to the device.

Trips are not fully planned in advance but not completely unplanned either. Tools should support iterative refinement of plans during the visit. If the tourist has expressed interest in a few sights by visiting their web pages earlier, the tools should automatically find information about distances to them and their opening hours to support making the final plan about their next activity.

Tourists should be able to share within their group their progress in creating the plan for the next activity. Existing tools often require one group member to be "in charge". Other group members would like to contribute in planning, but their opportunities are limited since they only intermittently hear what the primary user has found. To see the display of the device the primary user is holding, they have to peek over his or her shoulder, which can be difficult outdoors in variable lighting conditions. Instead, if they would see each other's progress on their own screen, they could concentrate on finding complementary information.

Tourists should be able to share within their group the route directions they are following. Other group members participate in recognizing landmarks whenever the primary user, who has the route directions shares enough information. Trying to see the display of the primary user while walking is even more difficult than in the stationary planning case described above. By presenting the directions in every group member's mobile, they would all have the full set of information and could participate every time they feel they have a contribution to make.

Navigation ceased to be tedious when the destination appeared in the distance and was recognized. Tools should provide this experience even if direct view to the destination is blocked. Seeing a virtual representation of the destination on the horizon (e.g. using augmented reality) when starting the navigation would be enough to confirm that the tourist is moving to the right direction. It would let the participant concentrate on enjoying the surroundings and exploring anything interesting on the way.

\section{CONCLUSIONS}

This paper describes an observational study where we shadowed 16 tourists and logged their mobile phone usage while they visited the center of Helsinki. We identified that tourists' navigation progressed in phases of in-situ planning, in-situ navigation, exploration and reflection but the participants moved through these phases fluidly and postponed the original goal if something interesting appeared along the way. The behavior in the exploratory phase complied with foraging theory if people had a strict time constraint or the area to explore was large. Otherwise the exploration was exhaustive. Both planning and in-situ navigation were collaborative but depended on the amount of related information the tourists shared between each other. By describing the richness of navigation and exploration activities we contribute towards a framework for assessing existing tools and developing new ones to cover the phases that existing tools do not yet handle.

\section{ACKNOWLEDGEMENTS}

We thank all participants, and Helsinki Tourist Information for helping to recruit them, as well as the HCI Helsinki community for comments in the various phases of the work. 


\section{REFERENCES}

1. Gregory D. Abowd, Christopher G. Atkeson, Jason Hong, Sue Long, Rob Kooper, and Mike Pinkerton. 1997. Cyberguide: a mobile context-aware tour guide. Wireless Networks 3, 5: 421-433. http://dx.doi.org/10.1023/A:1019194325861

2. Robert Albrecht, Riitta Väänänen, and Tapio Lokki. 2016. Guided by music: pedestrian and cyclist navigation with route and beacon guidance. Personal and Ubiquitous Computing 20, 1: 121-145. http://dx.doi.org/10.1007/s00779-016-0906-z

3. Gary L. Allen. 1998. Spatial abilities, cognitive maps, and wayfinding. In Wayfinding Behavior: Cognitive Mapping and Other Spatial Processes, R. G. Golledge (ed.). JHU Press, Baltimore, MD, 46-80.

4. J. Adam Beeco, Wei-Jue Huang, Jeffrey C. Hallo, William C. Norman, Nancy G. McGehee, John McGee and Cari Goetcheus. 2013. GPS Tracking of Travel Routes of Wanderers and Planners. Tourism Geographies 15, 3: 551-573. http://dx.doi.org/10.1080/14616688.2012.726267

5. Christian Bornträger, Keith Cheverst, Nigel Davies, Alan Dix, Adrian Friday, and Jochen Seitz. 2003. Experiments with Multi-modal Interfaces in a context aware city guide. Proceedings of 5th International Symposium on Human Computer Interaction with Mobile Devices and Services (MobileHCI '03), Springer-Verlag, 116-130. http://dx.doi.org/10.1007/978-3-540-45233-1_10

6. Barry Brown. 2007. Working the problems of Tourism. Annals of Tourism Research, 34, 2: 364-383. http://dx.doi.org/10.1016/j.annals.2006.09.003

7. Barry Brown, Moira McGregor and Eric Laurier. 2013. iPhone in vivo: Video Analysis of Mobile Device Use. In Proceedings of the SIGCHI conference on Human Factors in computing systems (CHI '13), 1031-1040. http://dx.doi.org/10.1145/2470654.2466132

8. Juan P. Carrascal and Karen Church. 2015. An In-Situ Study of Mobile App \& Mobile Search Interactions. In Proceedings of the SIGCHI conference on Human factors in computing systems (CHI '15). http://dx.doi.org/10.1145/2702123.2702486

9. Keith Cheverst, Nigel Davies, Keith Mitchell, Adrian Friday, and Christos Efstratiou. 2000. Developing a context-aware electronic tourist guide. Proceedings of the SIGCHI conference on Human factors in computing systems (CHI '00), 17-24. http://dx.doi.org/10.1145/332040.332047

10. Keith Cheverst, Nigel Davies, Keith Mitchell, and Paul Smith. 2000. Providing Tailored (Context-Aware) Information to City Visitors. Proceedings on International Conference on Adaptive Hypermedia and
Adaptive Web-Based Systems (AH 2000), 73-85. http://dx.doi.org/10.1007/3-540-44595-1_8

11. Abdallah El Ali, Sicco N.A. van Sas, and Frank Nack. 2013. Photographer paths: sequence alignment of geotagged photos for exploration-based route planning. Proceedings of the conference on Computer supported cooperative work (CSCW'13), 985-994. http://dx.doi.org/10.1145/2441776.2441888

12. European Commission. 2015. Bringing down barriers in the Digital Single Market: No roaming charges as of June 2017. Press release. Retrieved January 14, 2016 from http://europa.eu/rapid/press-release_IP-155927 en.htm

13. Eurostat. 2015. Tourism statistics at regional level. Retrieved January 17, 2016 from http://ec.europa.eu/eurostat/statistics-explained/ index.php/Tourism_statistics_at_regional_level

14. Denzil Ferreira, Vassilis Kostakos and Anind K. Dey. 2015. AWARE: Mobile Context Instrumentation Framework. Frontiers in ICT 2, 6:1-9. http://dx.doi.org/10.3389/fict.2015.00006

15. Simon Holland, David R. Morse and Henrik Gedenryd. 2002. AudioGPS: Spatial Audio Navigation with a Minimal Attention Interface. Personal and Ubiquitous Computing, 6, 4: 253-259. http://dx.doi.org/10.1007/s007790200025

16. Eva Hornecker, Stuart Swindells and Mark Dunlop. 2011. A mobile guide for serendipitous exploration of cities. In Proceedings of the International Conference on Human Computer Interaction with Mobile Devices and Services (MobileHCI'11), 557-562. http://dx.doi.org/10.1145/2037373.2037460

17. Matt Jones, Steve Jones, Gareth Bradley, Nigel Warren, David Bainbridge and Geoff Holmes. 2007. ONTRACK: Dynamically adapting music playback to support navigation. Personal and Ubiquitous Computing, 12, 7: 513-525. http://dx.doi.org/10.1007/s00779-007-0155-2

18. Alexander Keul and Anton Kühberger. 1997. Tracking the Salzburg tourist. Annals of Tourism Research 24, 4: 1008-1012. http://dx.doi.org/10.1016/S01607383(97)00038-8

19. Andreas Komninos, Peter Barrie, Vassilios Stefanis and Athanasios Plessas. 2012. Urban exploration using audio scents. In Proceedings of the international conference on Human-computer interaction with mobile devices and services (MobileHCI '12), 349358. http://dx.doi.org/10.1145/2371574.2371629

20. Jonathan Lazar, Jinjuan H. Feng and Harry Hochheiser. 2010. Research Methods in Human-Computer Interaction. John Wiley \& Sons. 
21. Alan Lew and Bob McKercher. 2006. Modeling Tourist Movements: A Local Destination Analysis. Annals of Tourism Research 33, 2: 403-423. http://dx.doi.org/10.1016/j.annals.2005.12.002

22. Daniel R. Montello and Corina Sas. 2006. Human Factors of Wayfinding in Navigation. In International Encyclopedia of Ergonomics and Human Factors W. Karwowski (ed.). CRC Press/Taylor \& Francis, Ltd. 2003-2008.

23. Stephen J. Payne and Andrew Howes. 2013. Adaptive Interaction: A Utility Maximization Approach to Understanding Human Interaction with Technology. Synthesis Lectures on Human-Centered Informatics, 6,1: 1-111. http://dx.doi.org/10.2200/S00479ED1V01Y201302HC I016

24. Martin Pielot, Benjamin Poppinga, Wilko Heuten, and Susanne Boll. 2012. Tacticycle: Supporting Exploratory Bicycle Trips. In Proceedings of the international conference on Human-computer interaction with mobile devices and services (MobileHCI '12), 369-378. http://dx.doi.org/10.1145/2371574.2371631

25. Daniele Quercia, Rossano Schifanella, and Luca Maria Aiello. 2014. The Shortest Path to Happiness: Recommending Beautiful, Quiet, and Happy Routes in the City. Proceedings of the 25th ACM conference on Hypertext and social media, 116-125. http://dx.doi.org/10.1145/2631775.2631799

26. Simon Robinson, Matt Jones, Parisa Eslambolchilar, Roderick Murray-Smith and Mads Lindborg. 2010. "I did it my way": Moving Away from the Tyranny of Turn-by-Turn Pedestrian Navigation. In Proceedings of the international conference on Human computer interaction with mobile devices and services (MobileHCI '10), 341-344. http://dx.doi.org/10.1145/1851600.1851660
27. Jay Rounds. 2004. Strategies for the Curiosity-Driven Museum Visitor. Curator: The Museum Journal 47, 4: 389-412. http://dx.doi.org/10.1111/j.21516952.2004.tb00135.x

28. David W. Stephens and John R. Krebs. 1986. Foraging Theory. Princeton University Press.

29. Lucy Suchman. 2006. Human-Machine Reconfigurations: Plans and Situated Actions, 2nd Edition. Cambridge University Press.

30. Robert Thornberg. 2012. Informed Grounded Theory. Scandinavian Journal of Educational Research 56, 3: 243-259. http://dx.doi.org/10.1080/00313831.2011.581686

31. Tuomas Vaittinen, Miikka Salminen and Thomas Olsson. 2013. City Scene: Field trial of a mobile streetimagery-based navigation service. Proceedings of the 15th International Conference on Human-Computer Interaction with Mobile Devices and Services (MobileHCI '13). http://dx.doi.org/10.1145/2493190.2493229

32. Dirk vom Lehn, Christian Heath and Hubert Knoblauch. 2001. Configuring exhibits. In Verbal Art Across Cultures, H. Knoblauch and H. Kotthoff (eds.). Gunter Narr Verlag, Tübingen, 281-297

33. Dan Wang and Daniel R. Fesenmaier. 2013. Transforming the Travel Experience: The Use of Smartphones for Travel. In Proceedings of the International Conference in Information and Communication Technologies in Tourism 2013. 58-69 http://dx.doi.org/10.1007/978-3-642-36309-2_6

34. World Tourism Organization. 2015. UNWTO Tourism Highlights, 2015 Edition. Retrieved January 14, 2016 from http://www.e-unwto.org/doi/book/ $10.18111 / 9789284416899$ 